\title{
Перспективы применения дендрохронологического метода для этноэкологических исследований историко-культурного наследия Тувы
}

Анна Ю. Майничева,

Новосибирский государственный университет архитектуры, дизайна и искусств, Российская Федерация,

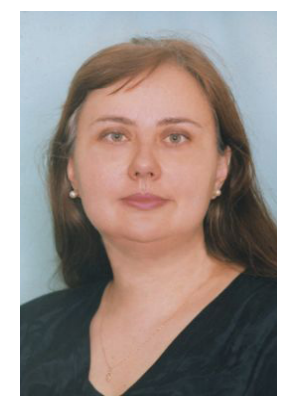

Владимир С. Мыглан,

Сибирский федеральный университет, Российская Федерация, Майя О. Филатова

Институт археологии и этнографии СО РАН, Российская Федерация

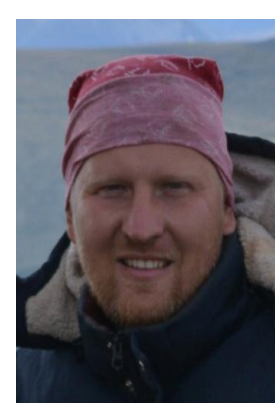

Метод дендрохронологии является неотъемлемой частью исследований по реконструкции условий внешней среды в прошлом, и календарной (относительной) датировки памятников истории и культуры. В Республике Тыва дендрохронологические исследования ведутся давно - с 1974 года. По этой причине назрела необходимость в систематизации данных о существующих древесно-кольцевых хронологиях и коллекциях археологической древесины для выявления перспектив применения дендрохронологического метода применительно к историко-культурному наследию Тувы.

Предметом исследования стали итоги и перспективы дендрохронологических исследований историко-культурного наследия Тувы методами дендрохронологии, объектом исследования - результаты уже выполненных и перспективных исследований. Источниковую базу составляет собранный авторами банк данных по дендрохронологическим исследованиям историко-культурного наследия Тувы.

Проведенный нами анализ источниковой базы показал, что дендрохронологические исследования в основном связаны с исследованием высокогорных районов республики (Монгун-Тайга, нагорье Сангилен), по которым удалось построить тысячелетние древесно-кольцевые хронологии. Степная часть республики изучена гораздо слабее, хотя, именно на этой территории расположены всемирно известные археологические памятники и архитектурное наследие. Коллекции образиов археологической древесины из курганов достаточно разрознены и дендрохронологическим исследованиям не подвергались. Как правило, они были календарно датированы при помощи радиоуглеродного метода. Однако, это не всегда

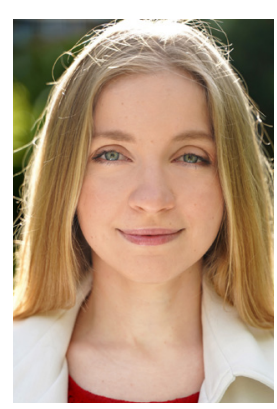
позволяет точно установить их календарный возраст (даты приходятся на «плато» на калибровочной радиоуглеродной кривой или при датировке не учитывается собственный возраст дерева относительно участка, взятого на радиоуглеродный анализ).

Выполненная систематизация дендрохронологических данных выявила два принципиальных момента: 1) в настоящее время для степной зоны Тувы имеется потенциал для построения древеснокольцевой хронологии, охватывающей первое тысячелетие до н. э.; 2) существующая сеть древеснокольцевых хронологий, охватывающая последние 778 лет, позволяет выполнять полномасштабные работы по исследованию архитектурного наследия Республики Тыва.

Ключевые слова: дендрохронология; этноэкология; архитектура; археология; Тува; Сибирь; культурное наследие

Экологическая часть исследования выполнена при финансовой поддержке Российского научного фонда проект № 19-14-00о28 «Экстремальные (катастрофические) засухи на юге Сибири за последнее тысячелетие», архитектурно-этнографическая часть исследования выполнена при поддержке Российского фонда фундаментальных исследований проект № 18-09-00469 «Новые методы в этнографии в информационную эпоху: оценка итогов и перспектив использования для исследования материальной культуры». Археологическая часть - М. О. Филатова работала в рамках темы НИР № 0264-2019-0010 «Реконструкция природных условий и способы адаптации к ним населения Евразии в четвертичном периоде» лаборатории «PaleoData» ИАЭТ СО РАН.

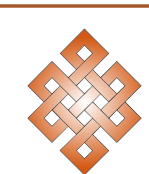

Для цитирования:

Майничева А. Ю., Мыглан В. С., Филатова М. О. Перспективы применения дендрохронологического метода для этноэкологических исследований историко-культурного наследия Тувы // Новые исследования Тувы. 2020 , № 4. C. 92-103. DOI: https://www.doi.org/10.25178/nit.2020.4.7

Майничева Анна Юрьевна - доктор исторических наук, главный научный сотрудник Новосибирского государственного университета архитектуры, дизайна и искусств. Адрес: 630099, Россия, г. Новосибирск, Красный пр., д. 38. Тел.: +7 (383) 33016-70. Эл. адрес: annmaini@gmail.com

Мыглан Владимир Станиславович - доктор исторических наук, ведущий научный сотрудник «Сибирской дендрохронологической лаборатории» Гуманитарного института Сибирского федерального университета. Адрес: 660041, Россия, г. Красноярск, пр. Свободный, д. 79. Тел.: +7 (391) 206-26-77. Эл. адрес: v.myglan@gmail.com

Филатова Майя Олеговна - младший научный сотрудник лаборатории «PaleoData» отдела геохронологии и кайнозоя Института археологии и этнографии СО РАН. Адрес: 630090, Россия, г. Новосибирск, пр. Лаврентьева, д. 17. Тел.: +7 (383) 332-08-63. Эл. адрес: mayasidorova12@gmail.com 


\title{
Prospects for applying the dendrochronological method to ethno- ecological studies of Tuvan historical and cultural heritage
}

\author{
Anna Yu. Mainicheva \\ Novosibirsk State University of Architecture, Design and Arts, Russian Federation, \\ Vladimir S. Myglan \\ Siberian Federal University, Russian Federation, \\ Maya O. Filatova \\ Institute of Archeology and Ethnography SB RAS, Russian Federation
}

\begin{abstract}
The dendrochronology method is an integral part of researching the reconstruction of environmental conditions in the past, and the calendar-based (relative) dating of historical and cultural monuments. In the Republic of Tuva dendrochronological studies have been ongoing since 1974. This explains the need for data classification in existing tree-ring timelines and collections of archaeological wood.

The article examines the results and prospects of dendrochronological studies of historical and cultural Tuvan heritage. Sources for the study are drawn from the databank of dendrochronological studies of Tuvan heritage, set up by the authors.

The analysis has shown that dendrochronological research is largely associated with the study of the high-mountainous regions of the republic (Mongun taiga, the Sangilen highlands) where it was possible to build some thousand-year tree-ring timelines. The steppe part of the republic is rather understudied, although it is there that world-famous archaeological sites and architectural heritage are located. The sample collections of archaeological wood from the barrows are rather fragmented and have not so far been studied using the dendrochronological method. Usually they were carbon-dated, however, this does not always make it possible to accurately determine their calendar age. The reason is that the dates fall on a "plateau" on the carbon calibration curve, or dating ignores the tree's own age relative to the site.

The classification of dendrochronological data revealed two aspects of utter importance: 1) it is currently possible to create a tree-ring timeline of the first millennium $B C ; 2)$ the existing network of tree-ring timelines makes it possible to conduct largescale research on the architectural heritage of the Republic of Tuva.
\end{abstract}

Keywords: dendrochronology; ethnoecology; architecture; archaeology; Tuva; Siberia; cultural heritage

\section{For citation:}

Mainicheva A. Yu., Myglan V. S. and Filatova M. O. Perspektivy primeneniia dendrokhronologicheskogo metoda dlia etnoekologicheskikh issledovanii istoriko-kul'turnogo naslediia Tuvy [Prospects for applying the dendrochronological method to ethno-ecological studies of Tuvan historical and cultural heritage]. New Research of Tuva, 2020, no. 4, pp. 92-103. (In Russ.). DOI: https://www.doi.org/10.25178/nit.2020.4.7

\section{Financing}

The ecological section of the study was supported by the Russian Science Foundation project No. 19-14-00028 "Extreme (catastrophic) droughts in the south of Siberia over the last millennium". The architectural and ethnographic sections of the study was supported by Russian Foundation for Basic Research, project No. 18-09-00469 "New methods in ethnography in information age: assessment of the results and prospects of use for the study of material culture”. The archaeological section, worked on by M. O. Filatova, was covered by research topic No. 0264-2019-0010 "Reconstruction of natural conditions and ways of adapting the Eurasian population to them in the Quaternary period" of the PaleoData laboratory of the IAET SB RAS.

MAINICHE VA, Anna Yurievna, Doctor of History, Chief Research Fellow, Novosibirsk State University of Architecture, Design and Arts. Postal address: 38 Krasny Pr., 630099 Novosibirsk, Russian Federation. Tel.: +7 (383) 330-16-70. E-mail: annmaini@gmail.com ORCID ID: 0000-0002-0784-4252 MYGLAN, Vladimir Stanislavovich, Doctor of History, Leading Research Fellow, Siberian Dendrochronological Laboratory, Humanitarian Institute, Siberian Federal University. Postal address: 79 Svobodny Pr., 660041, Krasnoyarsk, Russian Federation. Tel.: +7 (391) 206-26-77. E-mail:v.myglan@gmail.com ORCID ID: 0000-0002-5268-653X FILATOVA, Maya Olegovna, Junior Research Fellow, PaleoData Laboratory of the Geochronology and Cenozoic Department, Institute of Archeology and Ethnography, Siberian Branch, Russian Academy of Sciences. Postal address: 17 Lavrentiev Pr., 630090 Novosibirsk, Russian Federation. Tel.: +7 (383) 332-08-63. 


\section{Введение}

Метод дендрохронологии базируется на изучении уникальной последовательности годичных колец у древесных растений. В настоящее время он стал неотъемлемой частью исследований по реконструкции условий внешней среды, экстремальных природных явлений в прошлом, календарной и относительной датировки памятников истории и культуры. В гуманитарных исследованиях метод хорошо зарекомендовал себя и представлен значительным количеством научных работ на международной арене и в России (Шиятов и др., 2005; Мыглан и др., 2010; Быков, Малышева, 2012; Слюсаренко, Мыглан, 2015; Жарников, Гевель, Мыглан, 2017).

В Республике Тыва дендрохронологические исследования ведутся давно. За последнее десятилетие в этом направлении были достигнуты значительные успехи. Так, для высокогорных районов Республики Тыва была построена сеть длительных древесно-кольцевых хронологий протяженностью почти 3000 лет (Taynik et al., 2016, 2017), выполнена реконструкция экстремальных климатических событий за последние 1500 лет (Баринов, 2019) и изменчивости летних температур за последние 2000 лет (Buntgen et al., 2016). В то же время степная часть региона охвачена дендрохронологическими исследованиями намного слабее. В настоящий момент существуют разрозненные упоминания о древесно-кольцевых хронологиях (Myglan et al., 2016). Хотя с точки зрения этноэкологических исследований, именно степная зона представляет особый интерес, т. к. в ней расположена основная масса всемирно известных памятников археологического и архитектурного наследия.

Таким образом, в рамках статьи будет проведен обзор и подведение итогов дендрохронологических исследований степной части региона и существующих источников об историко-культурном наследии Тувы. Реализация этой задачи позволит очертить перспективы работ по календарному датированию археологических и архитектурных памятников малоизученной степной зоны Тувы.

\section{Систематизация дендрохронологических данных}

\section{Древесно-кольщевые хронологии по живым деревьям}

Обозначенная выше диспропорция в дендрохронологических исследованиях не случайна. В степной зоне построение дендрохронологической шкалы значительно затруднено из-за отсутствия старовозрастных деревьев, плохой сохранности отмершей древесины на дневной поверхности (сгорает в весенних палах или собирается на хозяйственные нужды населением). Несмотря на это, в последние годы достигнут существенный прогресс для степной части Тувы (фото 1). По участкам, расположенным в межгорных котловинах построена сеть из семи древесно-кольцевых хронологий (Sogly, Bora, Han, Ula, Hol, Tes, Nar), протяженностью 320 км (Myglan et al., 2016). Длина хронологий варьируется от 264 до 513 лет (рис. 1). Все хронологии хорошо коррелируют между собой (коэффициент корреляции между ними изменяется от 0.40 до 0.62) и пролеживается значимая связь (от 0.3 до 0.4) с хронологиями, построенными для схожих условий произрастания на Алтае и Монголии (там же). В настоящее время сотрудниками «Сибирской дендрохронологической лаборатории» проводится активная работа по построению тысячелетней древесно-кольцевой хронологии для степной зоны Сибири. Уже сейчас это позволило продлить хронологию Ula до 778 лет. Однако, несмотря на достигнутые успехи, длина древесно-кольцевых хронологий для степной зоны Республики Тыва не выходит за рамки последнего тысячелетия.

\section{Археологические памятники}

Более 50 лет идет накопление коллекций археологической древесины из памятников Тувы, но исследований, посвященных ее календарному датированию с помощью дендрохронологии, опубликовано немного.

Первая попытка датировать знаменитые археологические памятники скифской эпохи на территории Алтае-Саянского региона была сделана в конце 1950-х гг. И. М. Замоториным (Замоторин, 1959). Он изучил древесину из Больших Пазырыкских курганов Алтая, построил по ним «плавающую» хронологию и выявил, что курганы были сооружены всего за 48 лет. Исследователь установил, что курганы № 1 и № 2 были возведены в одно время, а не раньше, чем через 7 лет был сооружен курган № 4, затем через 30 лет курган № 3, а еще через 11 лет - курган № 5. При этом, достоверными результатами И. М. Замоторин предложил считать только данные по курганам № 1, № 2, № 5 (там же). Позже И. М. Замоторин исследовал курганы Туэкта-1 и Башадар-2. Он установил, что разница между курганом № 2 и Туэкта-1 составляет 130 лет, а Башадар-2 датировать не удалось (Замоторин, 1963). Установить 


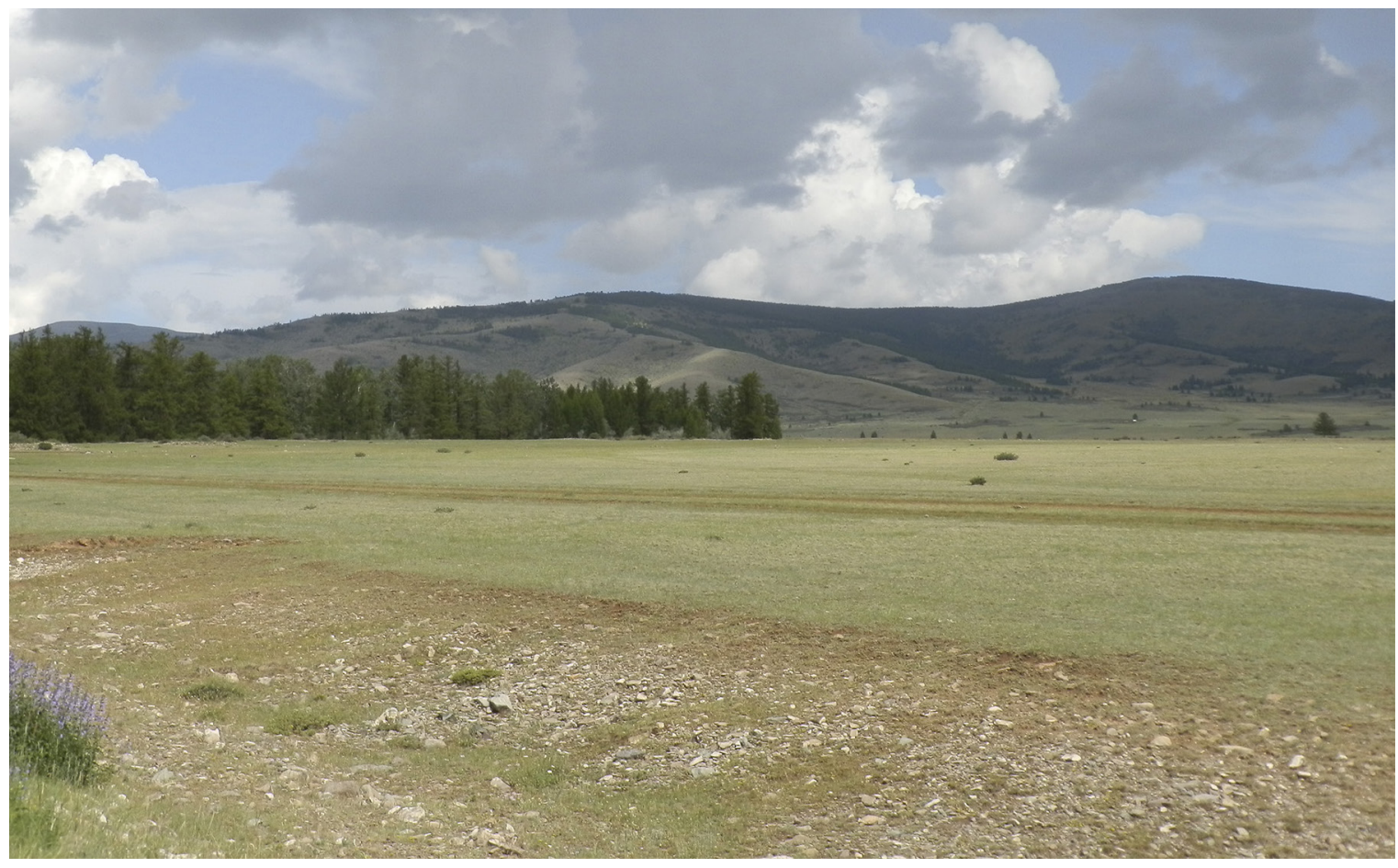

Фото 1. Пример степного участка в Республике Тыва.

Фото из архива «Сибирской дендрохронологической лаборатории» ${ }^{1}$, лесостепной участок у с. Сагль.

Photo. 1. An example of a steppe plot in the Republic of Tuva. Photo from the archive

of the Siberian Dendrochronological Laboratory, the forest-steppe area next to Sagly village.

календарные даты курганов в то время не представлялось возможным из-за отсутствия абсолютной древесно-кольцевой хронологии.

Первые исследования тувинского археологического наследия были сделаны Е. И. Захариевой в 1970-е гг. (Захариева, 1976). Она изучила образцы дерева из царского кургана Аржан и сопоставила их с данными курганов Алтая - Пазырык, Башадар и Туэкта (там же). Итогом ее работ стало определение последовательности сооружения курганов и пересмотр концепции И. М. Замоторина. Самым старым был признан Аржан, затем на 136 лет моложе Туэкта-1, еще на 21 год - Башадар-2, и еще на 84 года Пазырык-5, а через 16 лет были возведены остальные Пазырыкские курганы, согласно предыдущей последовательности. Таким образом, исследовательница сузила время сооружения Пазырыкских курганов до 43 лет. Для тувинской дендроархеологии она впервые ввела в научный оборот 42 образца из царского кургана Аржан, по которым построила обобщенную 252-летнюю «плавающую» хронологию (там же: 100,103$).$ К сожалению, дальнейшая судьба коллекции спилов неизвестна, и она считается утерянной.

Работу по датировке Алтае-Саянских курганов продолжил Л. С. Марсадолов (Марсадолов, 1988). Поводом послужило расхождение в датах в работах И. М. Замоторина и Е. И. Захариевой. Он изучил 41 древесный спил курганов Пазырык № 1, 2, 5, Туэкта-1, Шибе, Аржан и подтвердил выводы И. М. Замоторина. Последовательность сооружения курганов в итоге его работ выглядела следующим образом: первым был сооружен Аржан в Туве, затем через 200 +/- 5 лет Туэкта-1 на Алтае, а через 130 лет были возведены Пазырыкские курганы. Однако, в отношении Аржана небольшое количество образцов и использование данных Е. И. Захариевой не позволило выйти за уже достигнутые рамки для дендроархеологии Тувы.

Дальнейшие исследования были продолжены лишь в 2006 г., когда коллективом авторов В. С. Мыглан (Сибирский федеральный университет, г. Красноярск), И. Ю. Слюсаренко (Институт археологии и этно-

\footnotetext{
1 Лаборатория работает при Сибирском федеральном университете. Миссия лаборатории - изучение древесных колец с целью оценки климатических изменений, датирования событий прошлого, Сибирский федеральный университет, г. Красноярск, https://www.sibdendro.com/
} 
графии - далее ИАЭТ) СО РАН, г. Новосибирск), О.Ч. Ойдупаа (Тувинский государственный университет, г. Кызыл), Ю. Н. Гаркуша (ИАЭТ СО РАН, г. Новосибирск) были опубликованы данные анализа древесины из трех могильных сооружений царского кургана Аржан-2. В результате проведенной работы был введен в научный оборот 61 образец древесины и построена «плавающая» древесно-кольцевая хронология длиной 200 лет (Myglan et al., 2006: 132-138). К сожалению, календарно датировать курган не удалось по той же причине - отсутствие длительной календарно-привязанной древесно-кольцевой хронологии.

Кроме того, исследователи предприняли попытку сопоставить свои данные с хронологиями, полученными раннее Л. С. Марсадоловым и Е. И. Захариевой, но результаты привели лишь к новым вопросам методического характера и точности проведенной датировки. Авторы подвергли критике работу Л. С. Марсадолова, который писал, что: «перекрестным датированием установлено, что курган Аржан на $200 \pm 5$ лет древнее Туэкты-І» (Марсадолов, 1988: 75). Авторы отмечали, что это утверждение не совсем корректно, т. к., исходя из особенностей метода дендрохронологии, образцы могут датироваться только с точностью до года, в остальных случаях, считается, что образцы не датируются вообще (Мыглан, Слюсаренко, 2008: 380). Затем, с помощью перекрестной датировки с шестью образцами из кургана Аржан (которые были у них в наличии), исследователями была проверена обобщенная хронология Е. И. Захариевой. В результате было установлено, что «измеренные серии индивидуального прироста не датируются перекрестно с хронологией Zah (хронология Е. И. Захариевой. - прим. авторов). Это возможно только в том случае, если хронология Е. И. Захариевой не является «обобщенной схемой прироста годичных колец» древесины с кургана Аржан, что ставит под сомнение корректность ее использования для проведения перекрестной датировки других памятников» (там же: 381).

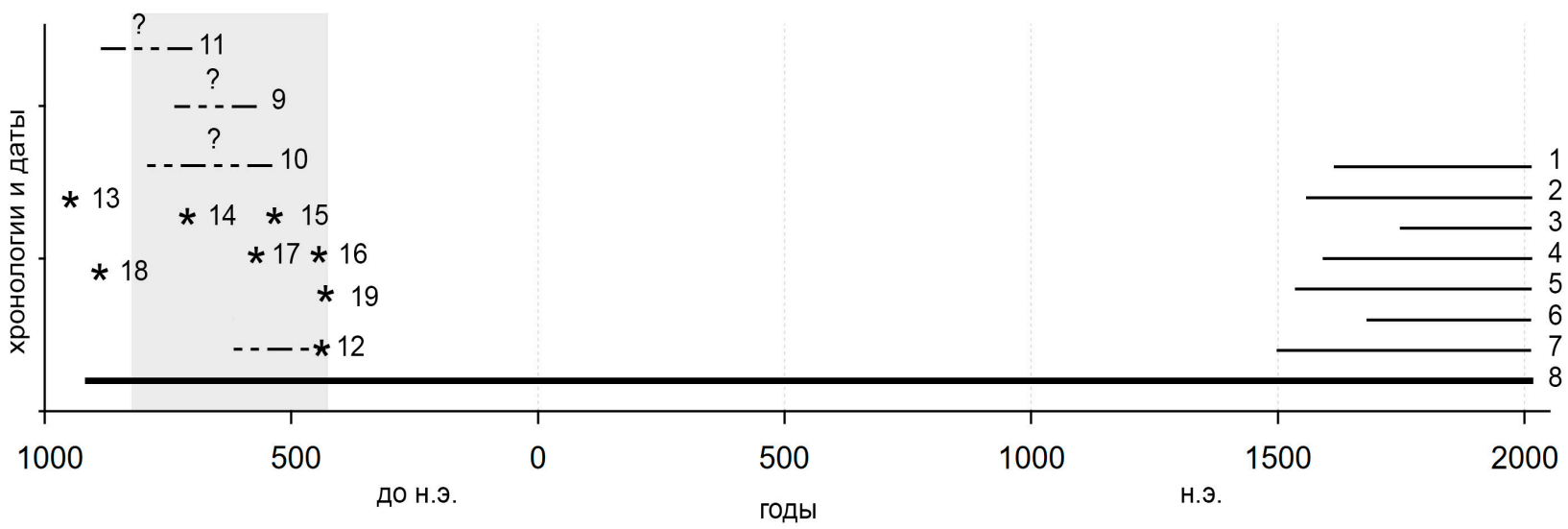

Рисунок 1. Существующие древесно-кольцевые хронологии и радиоуглеродные датировки древесины на территории Республики Тыва.

Прим.: Серым выделено «гальштатское плато» (Алексеев и др., 2005: 65); 1 - Календарно-привязанная древесно-кольцевая хронология (далее - ДКХ) Nar (Myglan et al., 2016); 2 - ДКX Tes (там же); 3 - ДКX Hol (там же); 4 - ДКX Ula (согласно данным Сибирской дендрохронологической лаборатории); 5 - ДКХ Han (там же); 6 - ДКХ Bora (там же); 7 - ДКХ Sogl (там же); 8 - ДКХ Mongun (Taynik et al., 2017); 9 - «Плавающая» ДКХ для кургана Аржан (Марсадолов, 1988: 74); 10 - «Плавающая» ДКХ для кургана Аржан (Захариева, 1976: 100, 103); 11 - «Плавающая» ДКХ для курганов Аржан-2 (Myglan et al., 2006: 132-138); 12 - Календарнопривязанная ДКХ с помощью радиоуглеродного анализа для курганов Догээ-Баары-2 (Алексеев и др., $2005: 54,248-249) ; 13$ Радиоуглеродные датировки для кургана Аржан (там же: 237); 14 - Радиоуглеродные датировки для курганов Аржан-2 (там же: 243); 15 - Радиоуглеродные датировки для курганов Аржан-4 (там же: 243); 16 - Радиоуглеродные датировки для кургана Аржан-Тарлаг (там же: 243); 17 - Радиоуглеродные датировки для курганов Сулуг-Хем-1 (там же: 237 ); 18 - Радиоуглеродные датировки для курганов Усть-Хадынныг-1 (там же: 237); 19 - Радиоуглеродные датировки для курганов Копто (там же: 248).

Fig. 1. Existing tree-ring chronologies and radiocarbon dating of wood in the Republic of Tuva.

Note: "Hallstatt plateau" is highlighted in gray (Alekseev et al., 2005: 65); 1 - Calendar-linked tree-ring chronology (hereinafter TRW) Nar (Myglan et al., 2016); 2 - TRW Tes (Ibid.); 3 - TRW Hol (Ibid.); 4 - TRW Ula (according to the Siberian Dendrochronological Laboratory); 5 - TRW Han (Myglan et al., 2016); 6 - BoH Bora (Ibid.); 7 - TRW Sogl (Ibid.); 8 - DKH Mongun (Taynik et al., 2017); 9 - "Floating" TRW for the Arzhan barrow (Marsadolov, 1988: 74); 10 - "Floating” TRW for Arzhan barrow (Zakharieva, 1976: 100, 103); 11 - "Floating” TRW for Arzhan-2 mounds (Myglan et al., 2006: 132-138); 12 - Calendar-linked TRW using radiocarbon analysis for Doge-Baary-2 mounds (Alekseev et al., 2005: 54, 248-249); 13 - Radiocarbon dating for the Arzhan mound (Ibid.: 237); 14 - Radiocarbon dating for Arzhan-2 mounds (Ibid.: 243); 15 - Radiocarbon dating for Arzhan-4 mounds (Ibid.: 243); 16 - Radiocarbon dating for the Arzhan-Tarlag mound (Ibid.: 243); 17 - Radiocarbon dating for Sulug-Khem-1 mounds (Ibid.: 237); 18 - Radiocarbon dating for Ust-Khadynnyg-1 mounds (Ibid.: 237); 19 - Radiocarbon dating for the Kopto mounds (Ibid.: 248). 
Дальнейших попыток календарного датирования археологической древесины в Республике Тыва с помощью дендрохронологического метода пока не производилось.

Несмотря на отсутствие абсолютной древесно-кольцевой хронологии, календарные датировки для большой группы курганов Тувы были выполнены путем радиоуглеродного датирования фрагментов древесины из памятников Аржан, Аржан-2, Аржан-4, Аржан-Тарлаг, Суглуг-Хем-1, Усть-Хадынныг-1, Копто, Догээ-Баары-2 (рис. 1). Данные масштабные исследования проводились на основе многолетних работ ряда российских и зарубежных археологов на территории Тувы: А. В. Адрианова, С. А. Теплоухова, Д. Г. Савинова, Ю. И. Трифонова, С. Н. Астахова, И. У. Самбу, Г. В. Длужневской (История Тувы, 2014), Д. Б. Данзын-оола (Дыртык-оол, 2006), М. Х. Маннай-оола (Маннай-оол, 1970), А. Д. Грача (Грач, 1980), М. П. Грязнова (Грязнов, 1980), А. М. Мандельштама (Мандельштам, 1983), К. В. Чугунова, Г. Парцингера, А. Наглера (Чугунов, 1999; Чугунов, Парцингер, Наглер, 2002, 2017 и др.), В. А. Семенова (Семенов, 2003), М. Е. Килуновской (Килуновская и др., 2015; Семенов, Килуновская, 1990), Н. А. Боковенко (Bokovenko, 1994) и др.

Результаты радиоуглеродного датирования были опубликованы в ряде отдельных работ, а затем сведены в монографию «Евразия в скифскую эпоху. Радиоуглеродная и археологическая хронология» (Алексеев и др., 2005). В ней собраны датировки 62 образцов древесины и разделены на три периода: XIII - сер. VII в. до н.э., VII-VI вв. до н.э., вторая половина VI-III в. до н. э. (там же: 236-249). С одной стороны, исследователям удалось датировать большой массив древесины уникальных археологических памятников, с другой стороны - вопрос о календарном времени все еще остается не решенным из-за так называемого «гальштатского плато» на калибровочной кривой протяженности около 400 лет - с 800 г. до н. э. до 400 г. до н. э., когда конвенциональный радиоуглеродный возраст практически не изменяется с увеличением календарного возраста и погрешность датирования возрастает до нескольких столетий. Именно на этот временной интервал попадают все скифские культуры Евразии (там же: 42-67). В этом случае, подтвердить или опровергнуть полученные датировки может помочь только дендрохронологический анализ, датирующий с точностью до года, но, как уже упоминалось выше, из-за отсутствия длительной древесно-кольцевой хронологии его проведение пока невозможно.

В настоящее время продолжается накопление древесного материала из археологических памятников Тувы. Уже сейчас, благодаря археологам К. В. Чугунову (Чугунов, Парцингер, Наглер, 2017), В. А. Семенову (Семенов, 2003), М. Е. Килуновской (Килуновская, Семенов, 2018), Т. Р. Садыкову, Н. А. Лазаревской, В. О. Глухову, В. А. Завьялову, Н. Ю. Смирнову (Семенов и др., 2014; Килуновская и др., 2015; Садыков, Каспари, Блохин, 2019), и дендрохронологам И. Ю. Слюсаренко и О. Ч. Ойдупаа собрана внушительная коллекция - более 670 образцов древесины с памятников Аржан, Аржан-2, Аржан-Тарлаг, Белое озеро-3, Экки-Оттуг-1, Саускен-1-3, 5, Догээ-Баары-1, 2, Сулуг-Хем-2, Кош-Пей-1, Чинге-Тей-1, Чкаловка, Огру-Хову-2, Чолтух, Бай-Даг-8, Атпак и Красная горка-2, 3. Надеемся, что датирование методом дендрохронологии древесины из вышеперечисленных курганов - дело ближайшего будущего.

Подводя итоги, можно сказать, что древесина археологических памятников в Туве пригодна для дендрохронологических исследований (уже есть опыт ее относительного и радиоуглеродного датирования). В то же время существует явная необходимость в построении длительной древесно-кольцевой шкалы для степной зоны, охватывающей два последних тысячелетия.

\section{Архитектурное наследие}

Появление и существование некоторых архитектурных объектов Тувы тесно связаны с историей региона, в том числе с появлением в конце XIX в. первых русских торговых факторий (в Шагонаре, ЧааХоле) и образованием земледельческих поселений (Туран, Уюк, Тарлык), а также с преобразованиями советского периода. В настоящее время некоторые сооружения советского периода имеют статус объектов культурного наследия, но необходимо проведение архитектурно-этнографических исследований по выявлению исторически и архитектурно значимых зданий более раннего периода для решения вопроса поставки их на учет как памятников культурного наследия.

Уже поставленные на учет сооружения также требуют пристального внимания исследователей. Прежде всего, это здания, в которых проходили важные исторические события, размещались правительственные, партийные и советские органы, жили политические и общественные деятели, деятели культуры. Многие из построек обладают интересными стилевыми особенностями, список их насчитывает более 50 наименований. Так, например, в г. Кызыле к ним относится здание музея политических репрессий, здание школы № 2, переданное правительством в дар тувинскому народу в 1940 г., православная церковь, здание первой русской школы в столице ТНР, дом, где в июле 1921 г. 

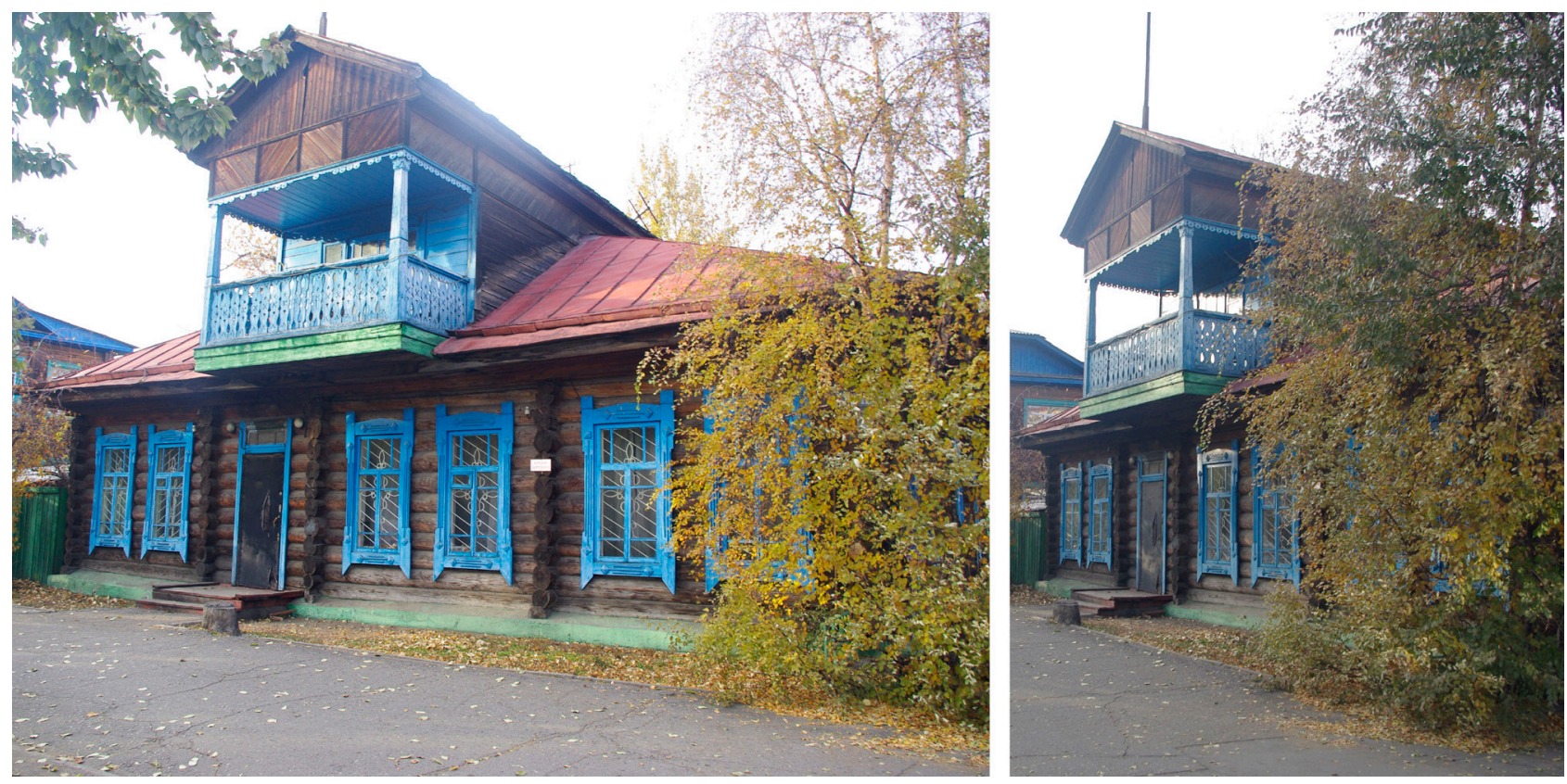

Фото 2 и 3. г. Кызыл, ул. Ленина, д. 20. Фото из архива «Сибирской дендрохронологической лаборатории».

Photo 2 and 3. 20 Lenin St., Kyzyl. Photo from the archive of the Siberian Dendrochronological Laboratory.

проходила первая тувинская конференция членов РКП (б), здание, где размещались ЦК ТНРП и ЦК ТРСМ (1925-1929 гг.), дом, в котором проживали писатели С. А. Сарыг-оол, С. Б. Пюрбю, О. К. Саган-оол, Б. Д. Ховенмей, А. А. Пальмбах, в г. Туране - церковь св. Иннокентия, здание ЦК ТНРП и правительства ТНР в 1932-1940 гг. и мн. др. Здания обладают существенными архитектурными достоинствами, которые требуют всестороннего архитектурно-этнографического анализа. Так, например, в доме, где в начале 1920-х гг. проходила первая тувинская конференция большевиков г. Кызыл, ул. Ленина, д. 20, стоит обратить внимание на объемно-планировочное решение: композицию и декоративное оформление фасадов, решение мезонина с колоннами и фронтоном, расположение балкона южного фасада и строительные конструкции в целом (фото 2-3).

Здание, где размещались ЦК ТНРП и ЦК ТРСМ (г. Кызыл, ул. Ленина, д. 17), отличается тем, что имеет крышу со слуховым окном, направленным на восток. Окна с деревянными наличниками с пропильной резьбой украшены объемными накладными элементами - пирамидками и узорами на лентах. Венцы сруба соединены в обло. В здании имеется деревянная лестница с фигурным ограждением, в коридоре - проемы, вырубленные в виде трехгранных арок (фото 4).

Кроме зданий, которые можно было бы включить в перечень памятников истории и культуры, существуют и так называемые этнографические объекты, представляющие интерес с точки зрения изучений традиций строительного дела. Несомненно, что работы по архитектурно-этнографическому обследованию зданий и сооружений Тувы должны выполняться с использованием современных информационных технологий, включающих лазерное сканирование, фотограмметрию, использование BIM (информационное моделирование зданий), виртуальные реконструкции, которые включены в методику полевых исследований (см. напр., Майничева, 2016, 2019ab; Mainicheva, Talapov, Zhang, 2017; Майничева, Талапов, Куликова, 2018), а также дендрохронологического анализа (Sidorova et al., 2017). До сих пор на территории Тувы не было датировано методом дендрохронологии ни одного памятника архитектуры, хотя их количество не уступает другим регионам России. Стоит отметить, что проведение такой работы помимо уточнения (верификации) дат сооружения построек, позволяет существенно продлить существующие хронологии по степной зоне Тувы и улучшить их качество (репликацию).

\section{Обсуждение}

Таким образом, несмотря на достигнутые успехи, в настоящее время на территории Тувы относительно календарного датирования памятников истории и культуры сохраняется ряд дискуссионных моментов. 


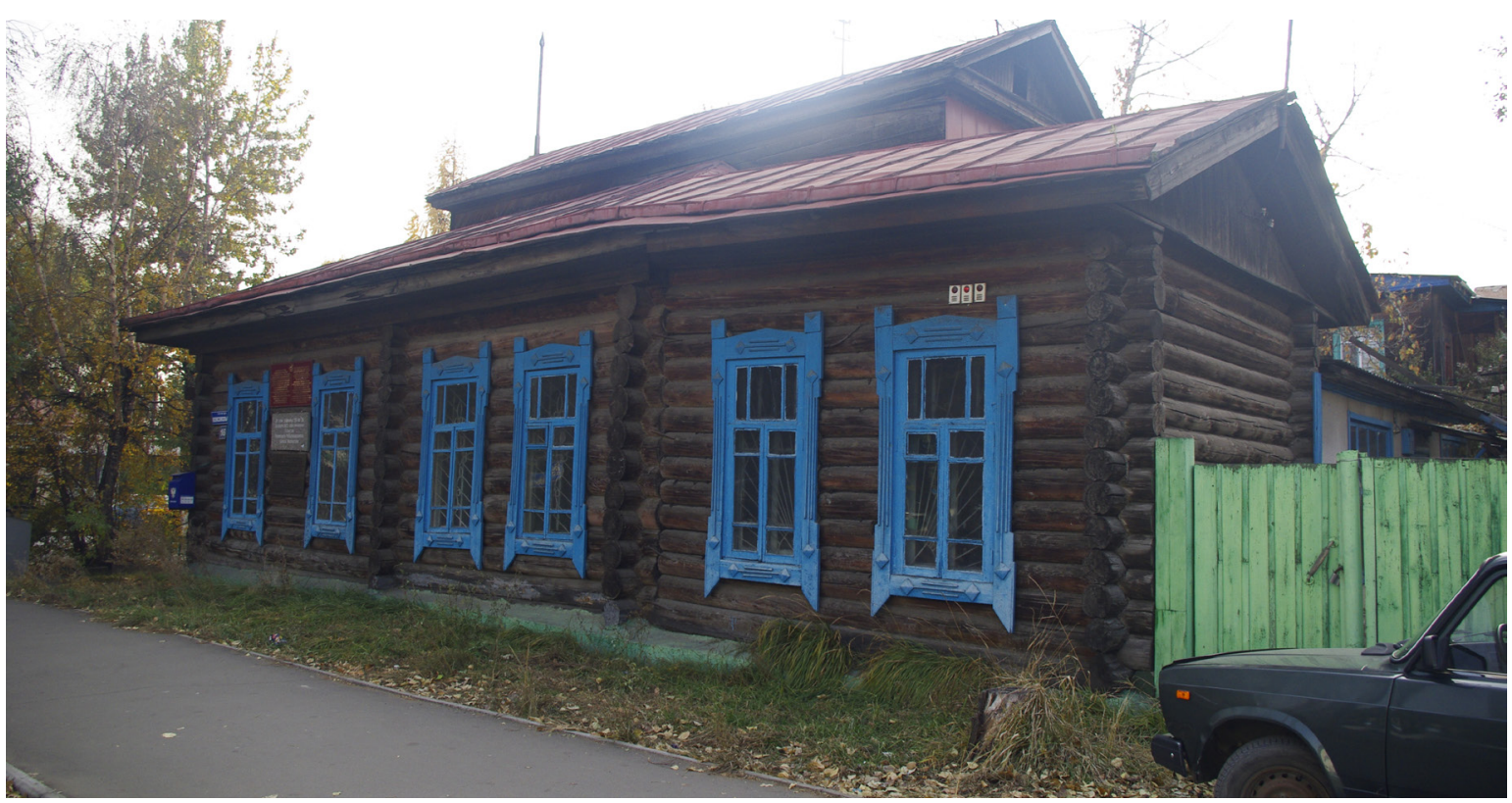

Фото 4. г. Кызыл, ул. Ленина, д. 17. Фото из архива «Сибирской дендрохронологической лаборатории».

Photo 4. 17 Lenin St., Kyzyl. Photo from the archive of the Siberian Dendrochronological Laboratory.

Опыт применения метода радиоуглеродного датирования (из-за «гальштатского плато» на калибровочной кривой) наглядно продемонстрировал, что в настоящее время существует необходимость построения длительной древесно-кольцевой хронологии для степных районов Тувы, которая могла бы стать универсальным инструментом для датирования памятников. Существующей сети хронологий по живым деревьям явно недостаточно для того, чтобы датировать памятники скифской эпохи, которые являются визитной карточкой Тувы (т. к. сохраняется временной зазор для условного периода с 1000 н. э. по 500 до н. э.). Решением данной проблемы могли бы стать систематический поиск и сбор палеодревесины, а также привлечение археологической древесины с памятников эпохи железа-средневековья. Это позволило бы связать воедино все ныне существующие разрозненные относительные хронологии по древесине археологических памятников и проверить точность радиоуглеродных датировок.

При этом, следует подчеркнуть, что несмотря на значительный потенциал имеющихся коллекций археологической древесины (которую еще предстоит обработать) существуют определенные сложности. Они связаны с тем, что далеко не все образцы принадлежат к одной древесной породе, имеют плотную структуру, достаточное количество колец для датирования и синхронные колебания годичного прироста. Именно эти факторы сильно влияют на успешность проведения работы по построению длительных древесно-кольцевых хронологий. Еще И. М. Замоторин отмечал, что при исследовании Алтае-Саянских памятников ограниченная выборка, отсутствие подкоровых колец затрудняет определение порубочной даты и датирование древесины курганов (Замоторин, 1963).

В настоящее время только памятники архитектурного наследия могли бы быть датированы по существующей древесно-кольцевой хронологии, но коллекции древесины со зданий еще никем не формировались. С выявленных архитектурных памятников еще предстоит отобрать образцы для дендрохронологического анализа, однако и в этой области имеются свои ограничения.

Таким образом, с одной стороны, исследование в данном регионе открывает широкие перспективы для будущего, с другой - вышеперечисленные проблемы сильно влияют на возможность сбора материала и построения длительной абсолютной древесно-кольцевой хронологии.

\section{Заключение}

Систематизация дендрохронологических данных показала, что в настоящее для степной зоны Тувы построена сеть хронологий по живым деревьям, охватывающая последние 778 лет. Собрана значительная коллекция археологической древесины из курганов, относящихся к первому тысячелетию 
до н. э., которая открывает широкие перспективы по календарному датированию археологических памятников и построению непрерывной древесно-кольцевой хронологии для первого тысячелетия до н. э. Наличие сети степных хронологий по произрастающим деревьям позволяет уже в настоящее время выполнить полномасштабные работы по исследованию архитектурного наследия Республики Тыва.

\section{СПИСОК ЛИТЕРАТУРЫ}

Алексеев, А. Ю., Боковенко, Н. А., Васильев, С. С., Дергачев, В. А., Зайцева, Г. И., Ковалюх, Н. Н., Кук, Г., Плихт, Й., Посснерт, Г., Семенцов, А.А., Скотт, Е. М., Чугунов, К. В. (2005) Евразия в скифскую эпоху: радиоуглеродная и археологическая хронология. СПб. : Thesa. 290 с.

Баринов, В. В. (2019) Экстремальные климатические события в Алтае-Саянском регионе за последние 1500 лет по дендрохронологическим данным: дисс. ... канд. биол. наук. Красноярск. 156 с.

Быков, Н. И., Малышева, Н. В. (2012) Дендрохронологический анализ исторического объекта горно-добывающего производства на Алтае // Журнал Сибирского Федерального университета. Серия: Биология. № 1. С. 89-96.

Грач, А. Д. (1980) Древние кочевники в центре Азии. М. : Наука. 256 с.

Грязнов, М. П. (1980) Аржан. Л. : Наука. 62 с.

Дыртык-оол, А. О. (2006) Музейное дело Тувы. Кызыл : ТывГУ. 85 с.

Жарников, 3. Ю., Гевель, Е. В., Мыглан, В. С. (2017) Бревенчатое наследие Сибири - старейшие сооружения деревянного зодчества Енисейска // Вестник Северного (Арктического) федерального университета. Серия: Гуманитарные и социальные науки. № 5. С. 24-36.

Замоторин, И. М. (1959) Относительная хронология Пазырыкских курганов // Советская археология. № 1. C. 21-30.

Замоторин, И. М. (1963) О возможности установления относительных датировок территориально удаленных сооружений методом анализа древесных стволов в условиях Горного Алтая // Советская археология. № 2. С. 131 -138.

Захариева, Е. И. (1976) Дендрохронологические исследования кургана Аржан // Советская археология. № 1. C. 100-107.

История Тувы (2014) : в 2 т. 2-е изд., перераб. и доп. / под общ. ред. С. И. Вайнштейна, М. Х. Маннай-оола. Кызыл: ОАО Тываполиграф. Т. І. 368 с.

Килуновская, М. Е., Лазаревская, Н. А., Садыков, Т. Р., Семенов, Вл. А. (2015) Исследования Тувинской археологической экспедиции ИИМК РАН в долине р. Ээрбек в 2014 г. // Бюллетень Института истории материальной культуры РАН. № 5. С. 193-224.

Килуновская, М. Е., Семенов, В. А. (2018) Исследования Тувинской археологической экспедиции // Археологические открытия. 2016 год / отв. ред. Н.В. Лопатин. М. : ИА РАН. 520 с. С. 439-441.

Майничева, А. Ю. (2016) Методика полевого этнографического исследования жилища русских в Сибири: проблемы выявления традиций и новаций // Баландинские чтения: сборник статей научных чтений памяти С. Н. Баландина / отв. ред. Д. Д. Гаркуша. Новосибирск : Новосиб. гос. ун-т. архитектуры, дизайна и искусств. Т. ХІ. 340 c. С. $52-55$.

Майничева, А. Ю. (2019а) Виртуальные реконструкции сибирских острогов и городов // Вестник Бурятского научного центра СО РАН. № 3 (35). С. 166-171.

Майничева, А. Ю. (2019b) Методика фиксации, документирования и информационного моделирования объектов материальной культуры: принципы и подходы // Баландинские чтения: сборник статей научных чтений памяти С. Н. Баландина / отв. ред. Д. Д. Гаркуша. Новосибирск : Новосиб. гос. ун-т. архитектуры, дизайна и искусств. T. XIV. 540 c. C. 57-60.

Майничева, А. Ю., Талапов, В. В., Куликова, С. О. (2018) Возможности применения ВІМ в этнографическом исследовании зданий и сооружений // Баландинские чтения: сборник статей научных чтений памяти С. Н. Баландина / отв. ред. Д. Д. Гаркуша. Новосибирск : Новосиб. гос. ун-т. архитектуры, дизайна и искусств. Т. XIII. 620 с. С. 67-70.

Мандельштам, А. М. (1983) Исследование на могильном поле Аймырлыг: некоторые итоги и перспективы // Древние культуры евразийских степей / отв. ред. В. М. Массон. Л. : Наука. 111 с. С. 25-33.

Маннай-оол, М. Х. (1970) Тува в скифское время (Уюкская культура). М. : Наука. 117 с.

Марсадолов, Л. С. (1988) Дендрохронология больших курганов Саяно-Алтая I тыс. до н. э. // Археологический сборник Государственного Эрмитажа. Вып. 29. С. 65-81. 
Мыглан, В. С., Ведмидь, Г. П., Майничева, А. Ю. (2010) Березово: историко-архитектурные очерки. Красноярск : Сиб. федерал. ун-т. 152 с.

Мыглан, В. С., Слюсаренко, И. Ю. (2008) Дендрохронологическое исследование курганов Аржан и Аржан-2 в Туве: подходы, проблемы, перспективы // Труды II (XVIII) археологического съезда в Суздале. Т. 3. С. 380 - 382.

Садыков Т., Каспари Д., Блохин Е. (2019) Раннескифский курган Туннуг-1: результаты первых работ на южной периферии памятника // Теория и практика археологических исследований. Т. 25. № 1. С. 29-38.

Семенов, В. А. (2003) Суглуг-Хем и Хайыракан - могильники скифского времени в Центрально-тувинской котловине. СПб. : Петербургское Востоковедение. 240 с.

Семенов, В. А., Килуновская, М. Е. (1990) Новые памятники раннего железного века в Туве // Информационный бюллетень Международной ассоциации по изучению культур Центральной Азии. Вып. 17. С. 36-47.

Семенов, В. А., Килуновская, М. Е., Глухов, В. О., Завьялов, В. А., Садыков, Т. Р., Смирнов, Н. Ю. (2014) Предварительные итоги исследований Тувинской археологической экспедиции в 2013 г. // Бюллетень Института истории материальной культуры РАН. № 4. С. 327-366.

Слюсаренко, И. Ю., Мыглан, В. С. (2015) Дендрохронологический анализ погребальных конструкций из курганов хунну в горах Ноин-Ула (Северная Монголия) // Мультидисциплинарные методы в археологии: новейшие итоги и перспективы / отв. ред. В. И. Молодин, С. Хансен. Новосибирск : Издательство ИАЭТ СО РАН. 448 с. С. $70-71$.

Чугунов, К. В. (1999) Некоторые итоги исследований могильника Догээ-Баары II // Круг знания. Научно-информационный сборник. Вып. 2. С. 33-46.

Чугунов, К. В., Парцингер, Г., Наглер, А. (2002) Элитное захоронение кочевников раннего скифского времени в Туве // Археология, этнология и антропология Евразии. Вып. 2. С. 115-124.

Чугунов, К. В., Парцингер, Г., Наглер, А. (2017) Царский курган скифского времени Аржан-2 в Туве. Новосибирск : ИАЭТ СО РАН. 500 с.

Шиятов, С. Г., Хантемиров, Р. М., Горячев, В. М., Агафонов, Л. И., Гурская, М. А. (2005) Дендрохронологические датировки археологических, исторических и этнографических памятников Западной Сибири // Археология и естественнонаучные методы / отв. ред. Е. Н. Черных, В. И. Завьялов. М. : Языки славянской культуры. 216 с. С. $43-57$.

Bokovenko, N. A. (1994) Tomb of Saka princes discovered in the Sayans, Siberia // New archaeological discoveries in Asiatic Russia and Central Asia / A. G. Kozintsev, V. M. Masson. St-Petersburg: Institute of History of Material Culture, Russian Academy of Sciences. 95 p. P. 48-53.

Buntgen, U., Myglan, V. S., Ljungqvist, F. C., McCormick, M., Di Cosmo, N., Sigl, M., Jungclaus, J., Wagner, S., Krusic, P. J., Esper, J., Kaplan, J. O., de Vaan, M. A. C., Luterbacher, J., Wacker, L., Tegel, W., Kirdyanov, A. V. (2016) Cooling and societal change during the Late Antique Little Ice Age from 536 to around 660 AD // Nature geoscience. Vol. 9. Issue 3. Pp. 231-236.

Mainicheva, A. Y., Talapov, V. V., Zhang, G. (2017) Principles of the information modeling of cultural heritage objects: the case of wooden buddhist temples // Archaeology, Ethnology and Anthropology of Eurasia. Vol. 45. Issue 2. Pp. 142-148.

Myglan, V. O., Oidupaa, O. C., Sljusarenko, I. Y., Garkusha Y. N. (2006) The royal tomb of Arjan-2, Tuva: A dendrochronological study // Archaeology, Ethnology and Anthropology of Eurasia. № 4. Pp. 130-138.

Myglan, V. S., Barinov, V. V., Taynik, A. V., Oidupaa, O. Ch. (2016) The constructing of a stepper tree-ring chronology network in the Tuva Republic in Russia // TRACE 2016, Tree Rings in Archaeology, Climatology and Ecology. Ed. by I. Malik, P. Kojs, A. Brauning. Bialowieza, Poland : University of Silesia. 122 p. P. 93.

Sidorova, M. O., Zharnikov, Z. Y., Dorzhu, Z. Y., Mainicheva, A. Y., Myglan, V. S. (2017) Dendrochronological Methods in the Architectural and Ethnographic Study of Russian Towns in Siberia: The Case of Tara, Omsk Region // Archaeology, Ethnology and Anthropology of Eurasia. Vol. 45. Issue 4. Pp. 122-131.

Taynik, A. V., Barinov, V. V., Oidupaa, O. Ch., Myglan, V. S., Reinig, F., Buntgen, U. (2016) Growth coherency and climate sensitivity of Larix sibirica at the upper treeline in the Russian Altai Sayan Mountains // Dendrochronologia. Vol. 39. P. 10-16.

Taynik, A. V., Barinov, V. V., Oidupaa, O. Ch., Myglan, V. S. (2017) Constructing of super long 3290-year tree-ring chronology for the Altai-Sayan region // TRACE 2017, Tree Rings in Archaeology, Climatology and Ecology. Ed. by I. Sviderskaya. Svetlogorsk : Siberian Federal University. 95 p. P. 34.

Дата поступления: 22.03.2020 2.

\section{REFERENCES}

Alekseev, A. Yu., Bokovenko, N. A., Vasil'ev, S. S., Dergachev, V. A., Zaitseva, G. I., Kovaliukh, N. N., Kuk, G., Plikht, I., Possnert, G., Sementsov, A. A., Skott, E. M. and Chugunov, K. V. (2005) Evraziia v skifskuiu epokhu: radiouglerodnaia i arkheologicheskaia khronologiia [Eurasia in Scythian times: radiocarbon and archaeological chronology]. St.-Petersburg, Thesa. 290 p. (In Russ.) 
Barinov, V. V. (2019) Ekstremal'nye klimaticheskie sobytiia v Altae-Saianskom regione za poslednie 1500 let po dendrokhronologicheskim dannym [Extreme climatic events in the Altai-Sayan region over the past 1500 years according to dendrochronological data]: Diss.... Candidate of Biology. Krasnoiarsk. 156 p. (In Russ.)

Bykov, N. I. and Malysheva, N. V. (2012) Dendrokhronologicheskii analiz istoricheskogo ob'ekta gorno-dobyvaiushchego proizvodstva na Altae [Dendrochronological studies of a historical mining site in the Altai]. Journal of the Siberian Federal University. Series: Biology, no. 1, pp. 89-96. (In Russ.)

Grach, A. D. (1980) Drevnie kochevniki v centre Azii [Ancient nomads in the center of Asia]. Moscow, Nauka. 256 p. (In Russ.)

Grjaznov, M. P. (1980) Arzhan [Arzhan]. Lenongrad, Nauka. 62 p. (In Russ.)

Dyrtyk-ool, A. O. (2006) Muzejnoe delo Tuvy [Museum work in Tuva]. Kyzyl, TyvGU. 85 p. (In Russ.)

Zharnikov, Z. Yu., Gevel', E. V. and Myglan, V. S. (2017) Brevenchatoe nasledie Sibiri - stareishie sooruzheniia dereviannogo zodchestva Eniseiska [The wooden heritage of Siberia: old log houses of Yeniseysk]. Vestnik Severnogo (Arkticheskogo) federal'nogo universiteta. Seriia: Gumanitarnye i sotsial'nye nauki, no. 5, pp. 24-36. (In Russ.)

Zakharieva, E. I. (1976) Dendrokhronologicheskie issledovaniia kurgana Arzhan [Dendrochronological studies of mound Arzhan]. Sovetskaia arkheologiia, no. 1. pp. 100-107. (In Russ.)

Istoriia Tuvy [The History Of Tuva] (2014) : in 2 vol. 2nd ed / ed. by S. I. Vanshtein and M. Kh. Mannai-ool. Novosibirsk, Nauka. Vol. I. 367 p. (In Russ.).

Kilunovskaia, M. E., Lazarevskaia, N. A., Sadykov, T. R., Semenov, Vl. A. (2015) Issledovaniia Tuvinskoi arheologicheskoi ekspeditsii IIMK RAN v doline r. Eerbek v 2014 g. [Research by the Tuva archaeological expedition of the IIMK RAS in the valley of the Eerbek river in 2014]. Biulleten' Instituta istorii material'noi kul'tury RAN, no. 5, pp. 193-224. (In Russ.)

Kilunovskaia, M. E. and Semenov, V. A. (2018) Issledovaniia Tuvinskoi arheologicheskoi ekspeditsii [Studies by the Tuva archaeological expedition]. Arheologicheskie otkrytiia. 2016 god [Archaeological discoveries. 2016]. Ed. by N. V. Lopatin. Moscow, IA RAN. 520 p. Pp. 439-441. (In Russ.)

Mainicheva, A. Yu. (2016) Metodika polevogo etnograficheskogo issledovaniia zhilishcha russkikh v Sibiri: problemy vyiavleniia traditsii i novatsii [Methods of field ethnographic research of Russian dwellings in Siberia: Problems of determining traditions and innovations]. In: Balandinskie chteniia: sbornik statei nauchnykh chtenii pamiati S. N. Balandina [Balandin Readings: a collection of articles in the memory of S.N. Balandin]. Novosibirsk, Novosib. gos. un-t. arkhitektury, dizaina i iskusstv. Vol. XI. 340 p. Pp. 52-55. (In Russ.)

Mainicheva, A. Yu. (2019a) Virtual'nye rekonstruktsii sibirskikh ostrogov i gorodov [Virtual reconstructions of Siberian forts and towns]. Vestnik Buriatskogo nauchn. tsentra SO RAN, no. 3(35), pp. 166-171. (In Russ.)

Mainicheva, A. Yu. (2019b) Metodika fiksatsii, dokumentirovaniia i informatsionnogo modelirovaniia ob'ektov material'noi kul'tury: printsipy i podkhody [Methods of fixing, documenting and information modeling of objects of material culture: principles and approaches]. In: Balandinskie chteniia: sbornik statei nauchnykh chtenii pamiati S. N. Balandina [Balandin Readings: A collection of articles in the memory of S.N. Balandin]. Ed. by D. D. Garkusha. Novosibirsk, Novosib. gos. un-t. arkhitektury, dizaina i iskusstv. Vol. XIV. 540 p. Pp. 57-60. (In Russ.)

Mainicheva, A. Yu., Talapov, V. V. and Kulikova, S. O. (2018) Vozmozhnosti primeneniia BIM v etnograficheskom issledovanii zdanii i sooruzhenii [The potential of using BIM in ethnographic studies of buildings and structures]. In: Balandinskie chteniia: sbornik statei nauchnykh chtenii pamiati S.N. Balandina [Balandin Readings: A collection of articles in the memory of S.N. Balandin]. Ed. by D. D. Garkusha. Novosibirsk, Novosib. gos. un-t. arkhitektury, dizaina i iskusstv. Vol. XIII. PP. 67-70. (In Russ.)

Mandel'shtam A. M. (1983) Issledovanie na mogil'nom pole Ajmyrlyg: nekotorye itogi i perspektivy [A study of the Aymyrlyg grave field: some results and prospects]. In: Drevnie kul'tury evrazijskih stepej [Ancient cultures of the Eurasian steppes]. Ed. by V. M. Masson. Leningrad, Nauka. 111 p. Pp. 25-33. (In Russ.)

Mannaj-ool, M. H. (1970) Tuva v skifskoe vremia (Ujukskaja kul'tura) [Tuva in Scythian time: the Uyuk culture]. Moscow, Nauka. 117 p. (In Russ.)

Marsadolov, L. S. (1988) Dendrokhronologiia bol'shikh kurganov Saiano-Altaia I tys. do n. e. [Dendrochronology of the large mounds of the Sayano-Altai of the 1st millennium BC]. Arkheologicheskii sbornik Gosudarstvennogo Ermitazha [Archaeological Collection of the State Hermitage Museum], vol. 29, pp. 65-81. (In Russ.)

Myglan, V. S., Vedmid', G. P. and Mainicheva, A. Yu. (2010) Berezovo: istoriko-arkhitekturnye ocherki [Berezovo: historical and architectural essays]. Krasnoyarsk, Sib. federal. un-t. 152 p. (In Russ.).

Myglan, V. S. and Sliusarenko, I. Yu. (2008) Dendrokhronologicheskoe issledovanie kurganov Arzhan i Arzhan-2 v Tuve: podkhody, problemy, perspektivy [Dendrochronological study of mounds Arzhan and Arzhan-2 in Tuva: approaches, problems, prospects]. Trudy II (XVIII) arkheologicheskogo s'ezda v Suzdale, vol. 3, pp. 380-382. (In Russ.) 
Sadykov, T., Kaspari, D. and Blohin, E. (2019) Ranneskifskij kurgan Tunnug-1: rezul'taty pervyh rabot na juzhnoj periferii pamjatnika [Early Scythian mound Tunnug-1: results of the first works on the southern periphery of the monument]. Teorija i praktika arheologicheskih issledovanij, vol. 25, no. 1, pp. 29-38. (In Russ.)

Semenov Vl.A. (2003) Suglug-Hem i Hayyrakan - mogil'niki skifskogo vremeni v Tsentral'no-tuvinskoi kotlovine [SuglugKhem and Khayyrakan: burial grounds of the Scythian time in the Central Tuva basin]. St. Petersburg, Peterburgskoe Vostokovedenie. 240 p. (In Russ.)

Semenov, Vl. A. and Kilunovskaja, M. E. (1990) Novye pamjatniki rannego zheleznogo veka v Tuve [New monuments of the Early Iron Age in Tuva]. Informatsionnyi biulleten' MAIKCA, vol. 17, pp. 36-47. (In Russ.)

Semenov, Vl. A., Kilunovskaia, M. E., Gluhov, V. O., Zav'ialov, V. A., Sadykov, T. R. and Smirnov, N. Yu. (2014) Predvaritel'nye itogi issledovanii Tuvinskoi arheologicheskoi ekspedicii v $2013 \mathrm{~g}$. [Preliminary results of studies of the Tuva archaeological expedition in 2013]. ijulleten' Instituta istorii material'noi kul'tury RAN, no. 4, pp. 327-366. (In Russ.)

Sliusarenko, I. Yu. and Myglan, V. S. (2015) Dendrokhronologicheskii analiz pogrebal'nykh konstruktsii iz kurganov khunnu v gorakh Noin-Ula (Severnaia Mongoliia) [A dendrochronological study of burial structures from the Xiongnu kurgans in the Noin Ula mountains, Northern Mongolia]. In: Mul'tidistsiplinarnye metody $v$ arkheologii: noveishie itogi i perspektivy [Multidisciplinary methods in archeology: the latest results and prospects]. Ed. by V. I. Molodin and S. Khansen. Novosibirsk, Izdatel'stvo IAET SO RAN. 448 p. Pp. 70-71. (In Russ.)

Chugunov, K. V. (1999) Nekotorye itogi issledovanij mogil'nika Dogjeje-Baary II [Some outcomes of studies at the Dogee-Baara II burial ground]. Krug znanija. Nauchno-informacionnyj sbornik, vol. 2, pp. 33-46. (In Russ.)

Chugunov, K. V., Partsinger, G. and Nagler, A. (2002) Elitnoe zakhoronenie kochevnikov rannego skifskogo vremeni $\mathrm{v}$ Tuve [Elite burial of nomads of the early Scythian time in Tuva]. Arheologia, etnologiia $i$ antropologiia Evrazii, vol. 2, pp. 115-124. (In Russ.)

Chugunov, K. V., Partsinger, G. and Nagler, A. (2017) Tsarskij kurgan skifskogo vremeni Arzhan-2 v Tuve [Royal Scythian mound Arzhan-2 in Tuva]. Novosibirsk, IAET SO RAN. 500 p. (In Russ.)

Shiiatov, S. G., Khantemirov, R. M., Goriachev, V. M., Agafonov, L. I. and Gurskaia, M. A. (2005) Dendrokhronologicheskie datirovki arkheologicheskikh, istoricheskikh i etnograficheskikh pamiatnikov Zapadnoi Sibiri [Dendrochronological dating of archaeological, historical and ethnographic monuments of Western Siberia]. In: Arkheologiia i estestvennonauchnye metody [Archaeology and methodologies of natural science] / ed. by E. N. Chernykh and V. I. Zav'ialov. Moscow, Iazyki slavianskoi kul'tury. 216 p. Pp. 43-57. (In Russ.).

Bokovenko, N. A. (1994) Tomb of Saka princes discovered in the Sayans, Siberia. In: New archaeological discoveries in Asiatic Russia and Central Asia / A. G. Kozintsev, V. M. Masson. St-Petersburg: Institute of History of Material Culture, Russian Academy of Sciences. 95 p. P. 48-53.

Buntgen, U., Myglan, V. S., Ljungqvist, F. C., McCormick, M., Di Cosmo, N., Sigl, M., Jungclaus, J., Wagner, S., Krusic, P. J., Esper, J., Kaplan, J.O., de Vaan, M.A.C., Luterbacher, J., Wacker, L., Tegel, W., Kirdyanov, A.V. (2016) Cooling and societal change during the Late Antique Little Ice Age from 536 to around 660 AD. Nature geoscience, vol. 9, issue 3, pp. $231-236$.

Mainicheva, A. Y., Talapov, V.V. and Zhang, G. (2017) Principles of the information modeling of cultural heritage objects: the case of wooden buddhist temples. Archaeology, Ethnology and Anthropology of Eurasia, vol. 45, issue 2, pp. 142-148.

Myglan, V. S., Barinov, V. V., Taynik, A. V. and Oidupaa, O. Ch. (2016) The constructing of a stepper tree-ring chronology network in the Tuva Republic in Russia. In: TRACE 2016, Tree Rings in Archaeology, Climatology and Ecology. Ed. by I. Malik, P. Kojs, A. Brauning. Bialowieza, Poland, University of Silesia. 122 p. P. 93.

Sidorova, M. O., Zharnikov, Z. Y., Dorzhu, Z. Y., Mainicheva, A. Y. and Myglan, V. S. (2017) Dendrochronological Methods in the Architectural and Ethnographic Study of Russian Towns in Siberia: The Case of Tara, Omsk Region. Archaeology, Ethnology and Anthropology of Eurasia, vol. 45, issue 4, pp. 122-131.

Taynik, A. V., Barinov, V. V., Oidupaa, O. Ch., Myglan, V. S., Reinig, F. and Buntgen, U. (2016) Growth coherency and climate sensitivity of Larix sibirica at the upper treeline in the Russian Altai Sayan Mountains. Dendrochronologia, vol. 39, pp. 10-16.

Taynik, A. V., Barinov, V. V., Oidupaa, O. Ch. and Myglan, V. S. (2017) Constructing of super long 3290-year treering chronology for the Altai-Sayan region. In: TRACE 2017, Tree Rings in Archaeology, Climatology and Ecology. Ed. by I. Sviderskaya. Svetlogorsk, Siberian Federal University. 95 p. P. 34.

Submission date: 22.03.2020. 